\title{
Imagens da simultaneidade e os impasses da narrativa - O caso da Synopsis historiae universalis (1766) de Johann Christoph Gatterer
}

\author{
André de Melo Araújo ${ }^{[1]}$
}

\section{Resumo}

No contexto acadêmico em que o pensamento histórico moderno se cientificiza, Johann Christoph Gatterer (1727-1799) publica um conjunto de seis tábuas históricas reunidas sob o título Synopsis historiae universalis (1766). Por meio delas, o autor procura apresentar uma visão geral da simultaneidade dos acontecimentos históricos e, assim, solucionar os impasses de representação narrativa da história universal. Ao analisar os seis fólios publicados por Gatterer, este artigo identifica nas tábuas de 1766 tanto a retomada de um gênero historiográfico já bastante difundido na época das Luzes, quanto sua reconfiguração feita em nome de uma nova semântica visual científica. Desse modo, leituras fundamentalmente logocêntricas do pensamento histórico moderno encontram limites ante a tese segundo a qual a informação visual deve ser considerada como um elemento importante no processo de cientifização da história na segunda metade do século XVIII. Palavras-chave: história e imagem; historiografia iluminista; tabelas históricas (gênero historiográfico).

\section{Imágenes de simultaneidad y las dificultades de la narrativa - El caso de la Synopsis historiae universalis} (1766) de Johann Christoph Gatterer

\section{Resumen}

En el contexto académico en el que el pensamiento histórico moderno se convirtió en una ciencia Johann Christoph Gatterer (17271799) publicó un conjunto de seis tablas históricas bajo el título Synopsis historiae universalis (1766). A través de ellas el autor procura presentar una visión general de los acontecimientos históricos así como solucionar las dificultades de la representación narrativa de la historia universal. A través del análisis de los seis folios publicados por Gatterer este artículo identifica un género bastante difundido en la época de la Ilustración, apuntando a las reconfiguraciones que acompañaron la emergencia de una nueva semántica visual científica. El artículo argumenta que la información visual debería ser considerada parte del proceso por medio del cual el pensamiento histórico ilustrado tardío se convirtió en ciencia, mostrando al mismo tiempo los límites de las interpretaciones logocéntricas tradicionales de la historia del pensamiento histórico moderno.

Palabras claves: historia e imagen; historiografía iluminista; tablas históricas (género historiográfico).

Images of simultaneity and the difficulties of the narrative - The case of Johann Christoph Gatterer's Synopsis historiae universalis (1766)

\section{Abstract}

In the academic context in which modern historical thought became a science, Johann Christoph Gatterer (1727-1799) published a set of six historical tables under the title Synopsis historiae universalis (1766). His aim was both to present an overview of the simultaneity of historical events and to overcome difficulties faced by the narrative representation of world history. By analyzing Gatterer's six folios, this article outlines the features of a historiographical genre that was already widespread at the time of the Enlightenment, pointing to the reconfigurations that accompanied the emergence of a new visual semantics in the sciences. The paper argues that visual information should be considered as part and parcel of the process through which late Enlightenment historical thought became science. By doing so, it also attempts to show the limits of traditional logocentric interpretations of the history of modern historical thought.

Keywords: history and image; Enlightenment historiography; historical tables (historiographical genre).

Images de la simultanéité et les impasses du récit - Le cas de la Synopsis historiae universalis (1766) de Johann Christoph Gatterer

\section{Résumé}

Dans le contexte académique dans lequel la pensée historique se scientificise, Johann Christoph Gatterer (1727-1799) publie un ensemble de six tables historiques réunies sous le titre de Synopsis historiae universalis (1766). Lauteur cherche à y présenter une vision générale de la simultanéité des événements historiques et, par conséquent, résoudre les impasses de la représentation narrative de l'histoire universelle. En analysant les six folios publiés par Gatterer, cet article identifie dans les tables de 1766 aussi bien la reprise d'un genre historiographique déjà fort répandu au temps des Lumières, que sa reconfiguration faite au nom d'une nouvelle sémantique visuelle scientifique. Ainsi, des lectures foncièrement logocentriques de la pensée historique moderne trouvent des limites devant la thèse selon laquelle l'information visuelle doit être considérée un élément important dans le processus de scientifisation de l'histoire dans la deuxième moitié du XVIIIe siècle.

Mots-clés: histoire et image, historiographie illuministe; tables historiques (genre historiographique). 
A

té as primeiras décadas do século XVIII, a história não havia se constituído como disciplina acadêmica autônoma, e servia sobretudo à teologia - no estabelecimento da cronologia bíblica, por exemplo - e à jurisprudência (Conrad, 2010, p.11). É apenas nas últimas décadas do século que os homens de letras procuram fundamentar uma identidade epistemológica própria à história à medida que se debatia sobre os critérios de evidência empírica para o conhecimento histórico, bem como se reforçava a necessidade de estabelecer um sistema em função do qual seria possível relacionar as partes integrantes da totalidade da história do homem e do mundo (Araújo, 2012). Na história da historiografia, esse processo de cientifização do pensamento histórico moderno encontra-se frequentemente associado à produção historiográfica ligada à universidade de Göttingen à época do Iluminismo tardio (Reill, 1975; Iggers, 1992, p.225-245; Jaeger e Rüsen, 1992, p.15). Uma das marcas centrais de tal processo diz respeito, por um lado, à importância conferida em Göttingen à crítica metódica das fontes históricas (Muhlack, 1991, p.396; Iggers, 2002, p.227; Iggers e Wang, 2008, p.28); por outro, à dificuldade de articulação narrativa de um sistema capaz de apresentar as conexões que fundamentam o projeto iluminista de representação da história universal. ${ }^{1}$

A cátedra de história geral em Göttingen foi ocupada por Johann Christoph Gatterer (1727-1799) entre os anos de 1759 e 1799. Formado na Universidade de Altdorf, Gatterer dedicara-se em sua juventude aos cursos de diplomática ministrados por Johann Heumann (1711-1760) e demonstrara forte interesse pela genealogia. Uma vez convidado para assumir o cargo de docente em Göttingen, Gatterer funda o Instituto Real de Ciências Históricas com o objetivo de aprofundar os estudos das ciências auxiliares da história e paralelamente começa a voltar seu olhar para o estudo da história universal. Em 1767, o autor expõe o núcleo da dificuldade que caracteriza o processo de cientifização do conhecimento histórico na Universidade de Göttingen:

[Quando] então o historiador já tiver traçado a disposição das narrativas de modo compreensível e inteiramente confortável para o leitor, então ele ainda precisa pensar como poderia surgir uma totalidade, um todo único e conectado, [tanto] a partir de todo esse material já colocado em ordem, [quanto a partir de outras] tantas totalidades independentes e isoladas. (...) É mesmo muito difícil dispor acontecimentos simultâneos, assim como nações simultâneas, na narrativa. (Gatterer, 1767, p.23 e 79)

Tendo em vista diversas formas de representação de "um todo único e conectado", Gatterer lembra a seus alunos e leitores que, "quando se aprende ou se lê a história das nações individualmente, uma após a outra", é preciso, no entanto, "estabelecer a simultaneidade por meio do uso de tabelas sincrônicas" (Gatterer, 1767, p.29-30). A saída apresentada por Gatterer para solucionar os impasses narrativos da história universal - a saber, o uso de tabelas sincrônicas - aponta tanto para a retomada de um gênero historiográfico bastante

'Cf. mais recentemente: Völkel (2012, p.341-342). 
difundido no século XVIII, ${ }^{2}$ quanto para sua reconfiguração por meio do uso de uma nova semântica visual científica. Trata-se de uma estratégia visual com a qual Gatterer procura ultrapassar a simples construção diacrônico-linear da narrativa histórica (Jordheim, 2014, p.515). Em que medida, portanto, as tentativas iluministas de representação visual da simultaneidade dos acontecimentos históricos devem ser consideradas como um elemento central no processo de cientifização da história? Eis a pergunta central deste artigo.

Na década de 1760, tabelas e diagramas já haviam se consolidado como um instrumento valioso de classificação, tipologização e sistematização do conhecimento científico. ${ }^{3}$ Ao procurar traduzir o resultado de observações empíricas em padrões mensuráveis e comparáveis, a semântica visual das ciências que se firma ao longo da Idade Moderna europeia acaba por apresentar alternativas eficazes de representação de um sistema totalizante. E essa é a herança historiográfica de Göttingen retomada, significativamente, por Daniel Gotthold Joseph Hübler (1734-1805) ao final do século das Luzes.

Diretamente inspirado nos estudos de Gatterer sobre a história universal, Hübler publica em 1796 uma série de tabelas sincrônicas da história dos povos (Hübler, 1799). No texto do prefácio à primeira edição, o autor deixa claro que, desde que começara a se dedicar ao estudo da história, sempre desejara que se tivesse à mão tabelas cronológicas que "estivessem de tal forma para a história, assim como os mapas estão para a Geografia” (Hübler, 1799, p.1v). Para tanto, Hübler declara não ter encontrado fórmula mais conveniente do que distribuir os acontecimentos históricos espacialmente no papel, de modo que eles fossem ordenados lado a lado, de acordo com a sequência dos anos (Hübler, 1799, p.1v). O autor ainda revela as dificuldades tipográficas que surgiram ao procurar realizar o projeto: o objetivo era que esses acontecimentos, na medida do possível, "aparecessem em uma [mesma] linha" (Hübler, 1799, p.1v). Assim, "a cronologia e o sincronismo seriam representados sensorialmente [sinnlich]", de tal forma que se poderia apreender com o olhar aquilo que, até então, era um esforço árduo da memória. ${ }^{4}$

Ao explorar as possibilidades de representação, em um único plano, da cronologia e do sincronismo, Hübler assume que tal iniciativa não é nova, visto que ele já a encontrara desenvolvida na Synopsis historiae universalis publicada por Gatterer em 1769 e, de forma ainda mais pormenorizada, nas Tabulae chronologicae de Johann Matthias Hase (1684-1742), impressas em 1743 (Hübler, 1799, p.1v). Na verdade não é de Hübler, mas de Gatterer a afirmação segundo a qual a história universal representa, para a história, o mesmo que o globo representa para a geografia (Gatterer, 1767, p.62). Por meio dessa

${ }^{2}$ No que diz respeito à presença de tabelas históricas nos currículos escolares de algumas regiões do Sacro Império Romano Germânico no século XVIII, veja-se, paradigmaticamente, as determinações administrativas referentes à cidade de Hannover no ano de 1717. Quanto às aulas das terças-feiras dos alunos da terceira classe, regulamenta o documento: "Hora VIIIva. Historiam Universalem instillet juxta dictum tam Benjam. Hederici, qvam Tabulae hunc in finen typis impressae." Cf. Stadt-Hannöversche Schul-Ordnung (1717, p.47) ${ }^{3}$ Martin Gierl, “Tabelle”, in: Friedrich Jaeger (Org.), Enzyklopädie der Neuzeit, Vol. 13, Stuttgart, J. B. Metzler, 2011, Col. $2 \mathrm{O} 2$.

${ }^{4}$ Hübler (1799, p.1v). A função mnemônica das tabelas históricas é destacada por Brendecke (2007, p.491-521, sobretudo p.501). 
analogia, Gatterer tinha em mente a imagem de uma totalidade conectada que poderia ser apreendida com um rápido olhar. Imagem esta assim verbalmente expressa em 1767, um ano após o professor de história geral em Göttingen ter publicado um conjunto de seis tábuas reunidas sob o título Synopsis historiae universalis (1766), e que Hübler conhecera apenas na segunda edição de 1769.

Os seis fólios publicados por Gatterer em 1766 podem ser divididos em dois subconjuntos que obedecem a lógicas e a padrões gráficos distintos. No primeiro grupo, aqui chamado de grupo A, encontram-se quatro tábuas numeradas de I a IV nas quais se distribui, em colunas previamentes definidas, a informação histórica relativa à história política, à história eclesiástica ou à história literária. No segundo grupo, doravante chamado de grupo B, encontram-se duas tábuas numeradas de I a II por meio das quais se procura representar a duração de diferentes povos na história universal.

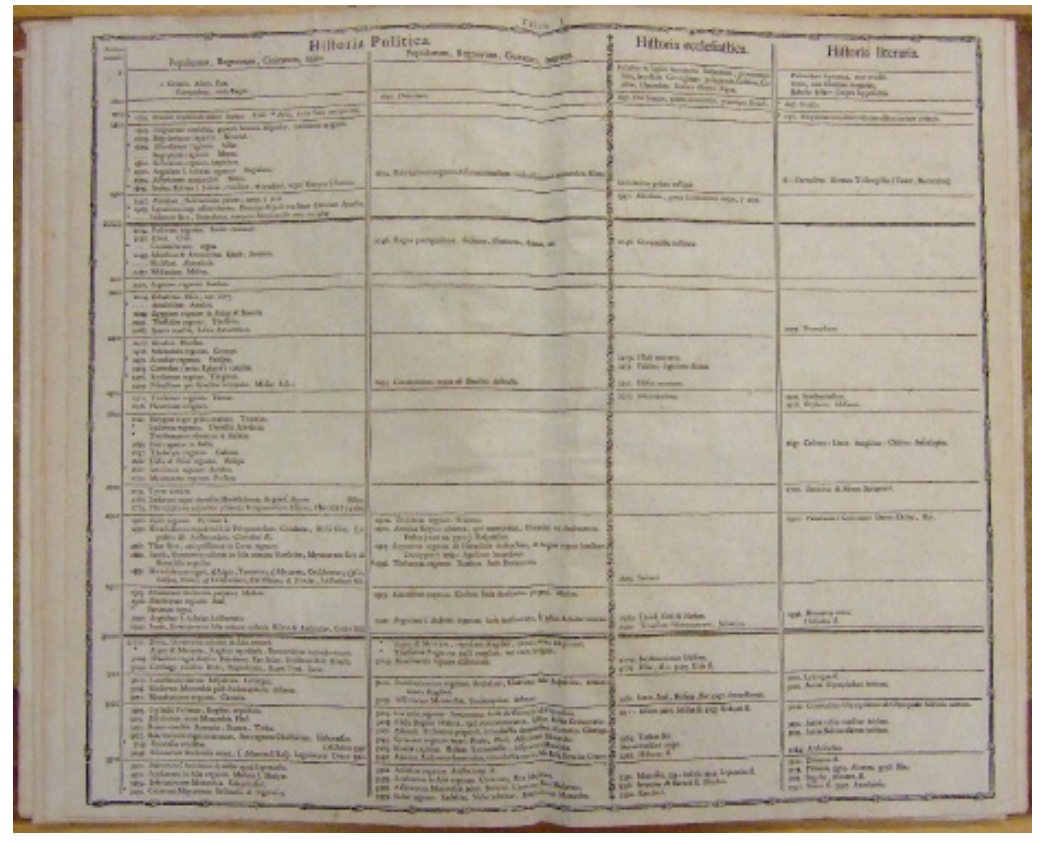

Padrão gráfico das tábuas do grupo A. Gatterer (1769) (Exemplar: Niedersächsische Staats- und Universitätsbibliothek Göttingen).

Os padrões gráficos dos dois grupos reproduzidos correspondem, respectivamente, à retomada do gênero historiográfico das tabelas históricas em Göttingen e à sua reconfiguração por meio de uma nova semântica visual científica com que Gatterer procurava solucionar impasses de representação narrativa da história universal. Para que se possa, no entanto, avançar com a tese segundo a qual práticas visuais passam a ser um elemento fundamental no processo de cientifização do conhecimento histórico ao longo da segunda metade do século XVIII, deve-se adotar dois caminhos paralelos de análise. No primeiro momento, iremos estudar tanto as características morfológicas quanto os aspectos epistemológicos do gênero historiográfico no qual o conjunto de seis fólios da obra Synopsis historiae universalis se insere. Em um 


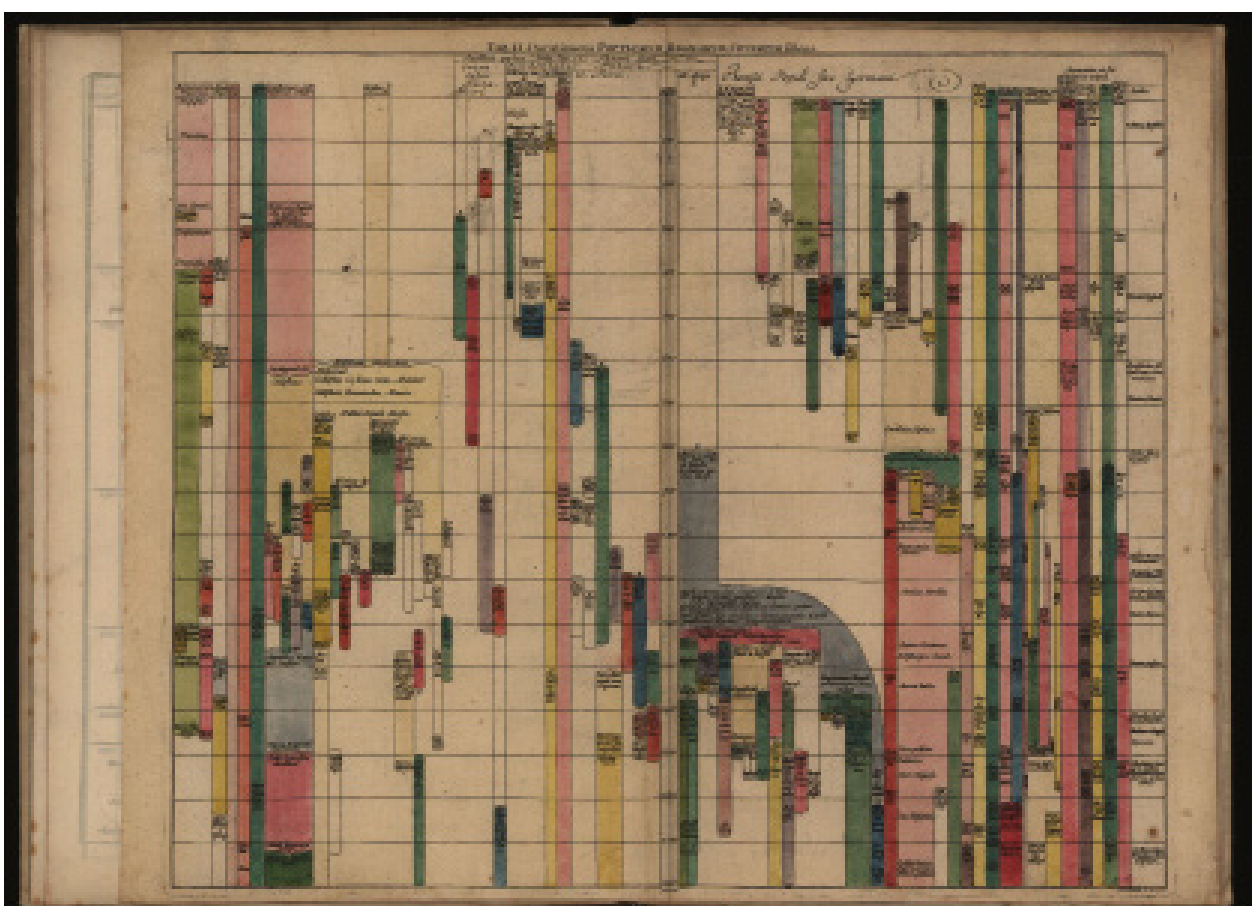

Padrão gráfico das tábuas do grupo B. Gatterer (1766) (Exemplar: Universitäts- und Landesbibliothek Sachsen-Anhalt).

segundo passo, verificaremos as formas visuais de representação da precisão científica e da unidade sistemática necessárias ao projeto intelectual das Luzes para que possamos, por fim, retomar o debate em torno da dificuldade de articulação narrativa de um sistema por meio do qual seja possível apresentar as conexões que fundamentam o projeto iluminista de representação da história universal. Aqui, as leituras fundamentalmente logocêntricas do pensamento histórico moderno encontrarão limites ante a tese segundo a qual a informação visual deve ser considerada um elemento central no processo de cientifização do pensamento histórico à época do Iluminismo tardio.

\section{As tabelas históricas em perspectiva historiográfica}

Já na Antiguidade se encontra disseminada a prática de compor listas sucessórias e genealógicas de senhores territoriais (Steiner, 2008, p.41). Tais listas, no entanto, só podem "ser consideradas como 'tabelas históricas' quando a elas se adicionam os anos ou outras datas de referência" (Brendecke, 2004, p.158). Do ponto de vista morfológico, as tabelas históricas são caracterizadas, portanto, pela disposição visual da informação de tal modo que seja possível cruzar a informação referente à identificação nominativa e/ou descritiva dos acontecimentos históricos com aquela referente à sua respectiva localização temporal. À exploração desse cruzamento remontam formas híbridas entre texto e tabela, tais como as crônicas manuscritas produzidas durante a Idade Média (Brendecke, 2004, p.160; 2007, p.498). Na Crônica concebida por 
Eusébio de Cesareia (c. 260-339), procurava-se encontrar a correspondência cronológica - ou seja, procurava-se indicar visualmente a sincronização entre os acontecimentos relacionados à história profana e aqueles narrados no texto bíblico (Steiner, 2008, p.42; Rosenberg e Grafton, 2010, p.15, 26 e 27; Grafton e Williams, 2008, p.133).

Com a expansão da cultura impressa e o refinamento da disposição visual da informação histórica no papel em função do uso de tipos gráficos menores (Brendecke, 2004, p.162), o Sacro Império Romano Germânico passa a ser o grande centro europeu de publicação de tabelas históricas (Steiner, 2008, p.131 e 157). Essa é época em que Paulus Constantinus Phrygio (1483-1543) escreve comentários ao Antigo Testamento e publica, em 1534, uma crônica sincrônica do mundo (Phrygio, 1534). Trata-se de uma obra seminal na moderna constituição do gênero das tabelas históricas, sobretudo por dispor, no mesmo plano gráfico, a história bíblica e a história profana no contexto das reformas religiosas. A crônica de Phrygio segue uma lógica regular de representação total do tempo sem que se apresentem saltos entre a unidade temporal explicitada nesse caso, os anos. Consequentemente, a obra é marcada pela presença de espaços em branco referentes aos anos aos quais não se associa nenhum fato histórico marcante.

\section{"a cronologia e o sincronismo seriam representados sensorialmente [sinnlich],' de tal forma que se poderia apreender com o olhar aquilo que, até então, era um esforço árduo da memória}

Nas primeiras páginas, Phrygio organiza a sequência cronológica dos anos em função do plano horizontal da leitura, e as colunas marcam intervalos temporais regulares e simétricos, de forma que as páginas apresentam os acontecimentos referentes a uma década, sendo cada página, consequentemente, composta de dez colunas. Em função do aumento de eventos históricos mencionados e com o avanço da cronologia em direção ao tempo presente, as colunas passam a ocupar um espaço mais largo nas páginas impressas. Phrygio dedica nove, posteriormente seis colunas por página até o final do volume. A crônica de 1534 não obedece, portanto, a uma regra rígida e constante de disposição espacial do tempo na sua representação gráfica sobre o papel, uma vez que o espaço, em milímetros, dedicado a cada unidade temporal mínima (nesse caso, os anos), aumenta ao longo da obra.

Para além da quebra da uniformidade espacial na disposição das colunas, a organização visual da informação proposta na obra de Phrygio dificulta a apreensão do padrão da simultaneidade. A dificuldade surge uma vez que a direção ocidental da leitura - da esquerda para a direita e de cima para baixo - impõe, nesse caso, primeiramente a leitura de todos os anos, posteriormente 
dos acontecimentos referentes a uma unidade político-cultural distinta, para que o olhar possa retomar, em seguida, a mesma lógica agora referente a uma outra unidade definida no eixo das colunas. É, portanto, a inversão gráfica do eixo das colunas e das linhas que se mostra mais adequada para organizar visualmente os acontecimentos históricos. Nota-se que ao longo da Idade Moderna o tempo passa a ocupar "quase sempre a dimensão vertical das tábuas de observação" (Daston, 2011, p.99). Essa tendência se verifica ao se compararem os modos de organização visual da informação científica, seja o objeto da observação registrado nas tábuas as perturbações lunares, a temperatura, a incidência de doenças, ou a sucessão dos acontecimentos históricos.

Eis que na Chronologia de Johann Funck (1518-1666), publicada em 1545, o tempo ocupa a dimensão vertical da página. ${ }^{5}$ Trata-se, aqui, de uma das tabelas cronológicas mais citadas entre os letrados nos séculos XVI e XVII. Nessa obra de Funck, a sequência cronológica dos anos surge sem saltos no papel com o objetivo de apresentar equivalências entre os diversos sistemas de contagem do tempo, informação esta igualmente presente na obra de Phrygio. Em Funck, no entanto, enquanto o fluxo do tempo representado nas linhas permanece graficamente regular, as colunas vão se subdividindo ao longo das páginas com o aumento das unidades político-culturais consideradas na obra.

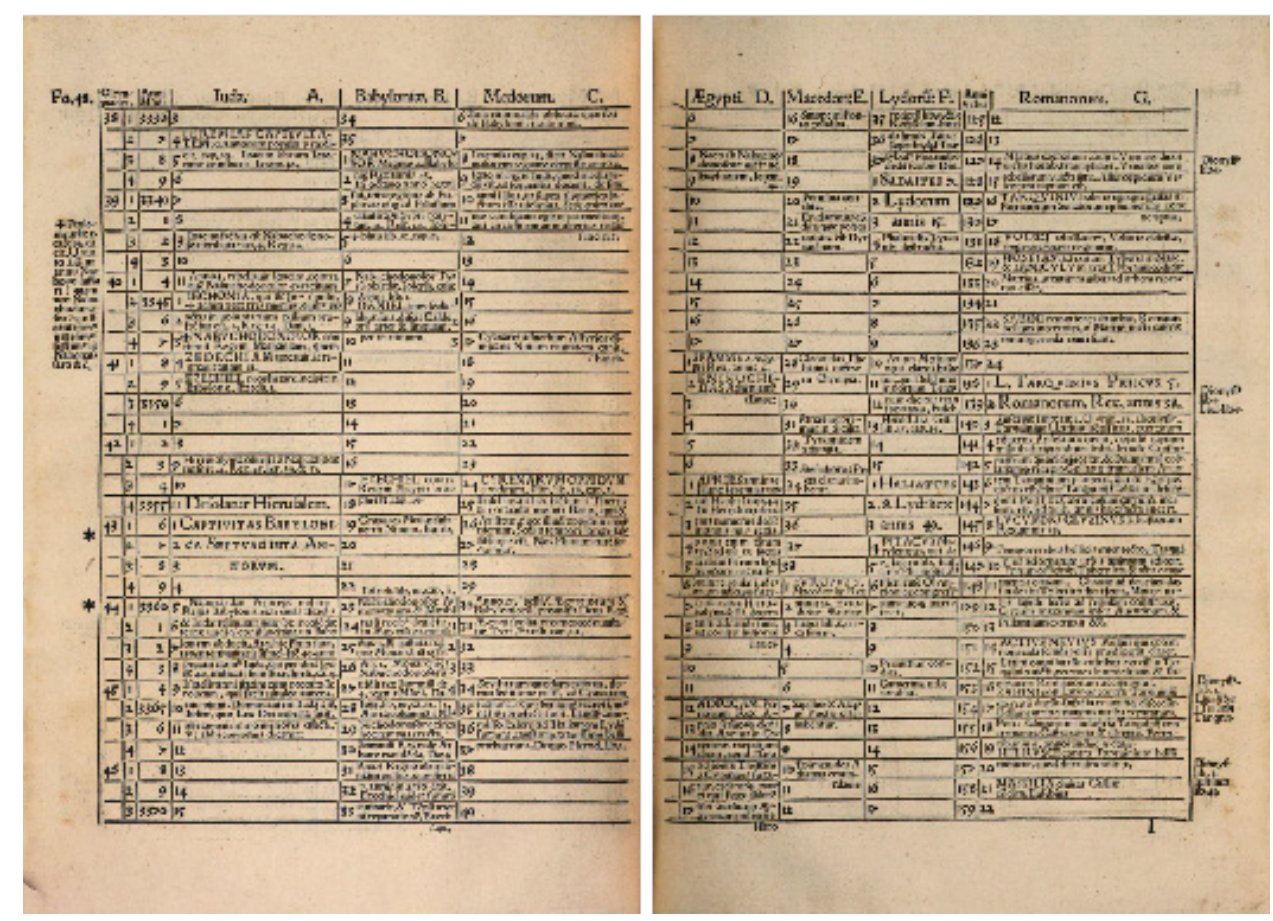

Funck (1545) (Exemplar: Bayerische Staatsbibliothek München).

${ }_{5}^{5}$ Funck (1545). Em comparável esquema gráfico, Funck publica mais uma Chronologia em 1552, sendo o espaço destinado às linhas um pouco mais largo, se comparado àquele da obra anterior, visto que o volume de informações colecionadas sobre a História Universal cresce ao longo de seu trabalho de pesquisa. Cf. Funck (1552). 
No mesmo ano em que Funck publica sua Chronologia, Johann Sleidan (1506/1508?-1556) começa a trabalhar no texto de sua história da Reforma religiosa. Um ano após a morte do autor protestante, saem publicadas suas Tabulae in libros historiarum de religione et republica; obra que, pela disposição gráfica da informação, é de difícil classificação entre os gêneros das tabelas cronológicas e da história narrativa (Baumgarten, 1892, p.454-461). As Tabulae de Sleidan encontram-se divididas em colunas que organizam os acontecimentos da história da igreja e da história civil; colunas estas que, por sua vez, subdividem-se entre os acontecimentos ocorridos em solo germânico e aqueles que tiveram lugar para além das fronteiras do Sacro Império. O texto inicia significativamente com o ano de 1517, demonstrando claro engajamento protestante: "Leone Pontifice, generalis peccatorum remissio, quam Indulgentias uocant, uaenalis per omnem orbem Christianum proscribitur" (Sleidanus, 1557, p.Alr). Mas, nesse caso, do ponto de vista da representação visual do conhecimento histórico, é o texto que confere limite ao tempo. Tanto é que não há regularidade gráfica nas linhas que indicam os anos, como se percebe, visualmente, nos momentos de transição entre os anos marcados nas Tabulae de Sleidan.
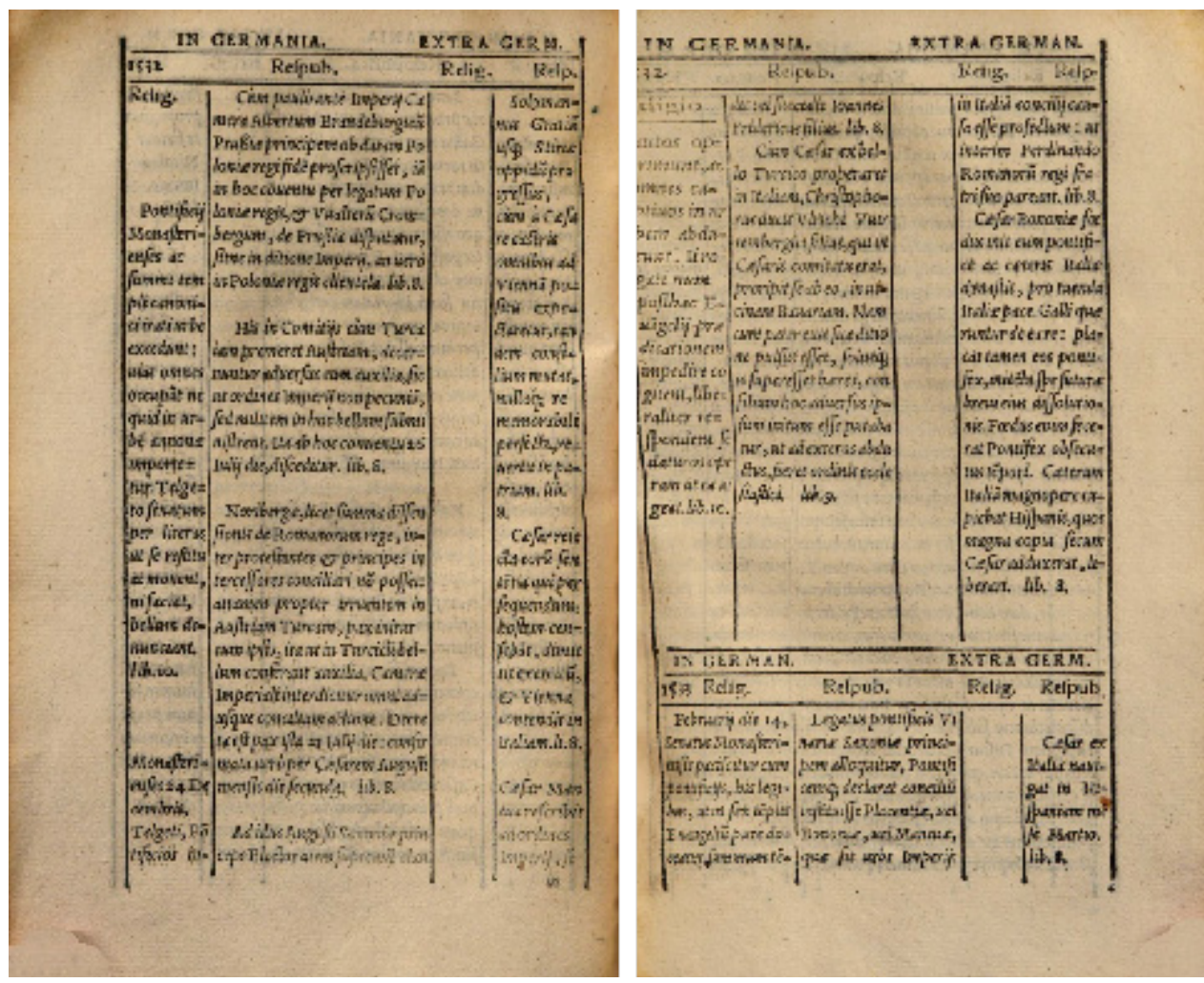

Sleidanus (1557) (Exemplar: Regensburg, Staatliche Bibliothek).

Várias são as tabelas impressas ao longo da Idade Moderna cujo domínio gráfico é dado pelo fluxo do texto. Nesse sentido, um exemplo bastante representativo é a Chronologia historiae Herodoti et Thucydidis (Chytraeus, 1563) de David Chytraeus (1531-1600), obra esta que servia de base para as 
preleções acadêmicas do autor. Mas tendo por base sobretudo o texto da Chronologia de Chytraeus, um de seus alunos, Ubbo Emmius (1547-1625), publica em 1619 uma Opvs chronologicum novvm, na qual informações biográficas e genealógicas associadas a um determinado ano surgem com frequência (Emmius, 1619). Nas tabelas inseridas no meio do volume publicado por Emmius pode-se, no entanto, observar um novo padrão gráfico de disposição visual da informação histórica que se organiza em torno de uma régua cronológica impressa no meio das páginas. Cada traço indicado na régua equivale a um período de 50 anos. Desse modo, Emmius apresenta um modelo de organização das tabelas históricas no qual a disposição da informação no papel obedece rigorosamente a um projeto regular e constante de representação gráfica do fluxo do tempo.

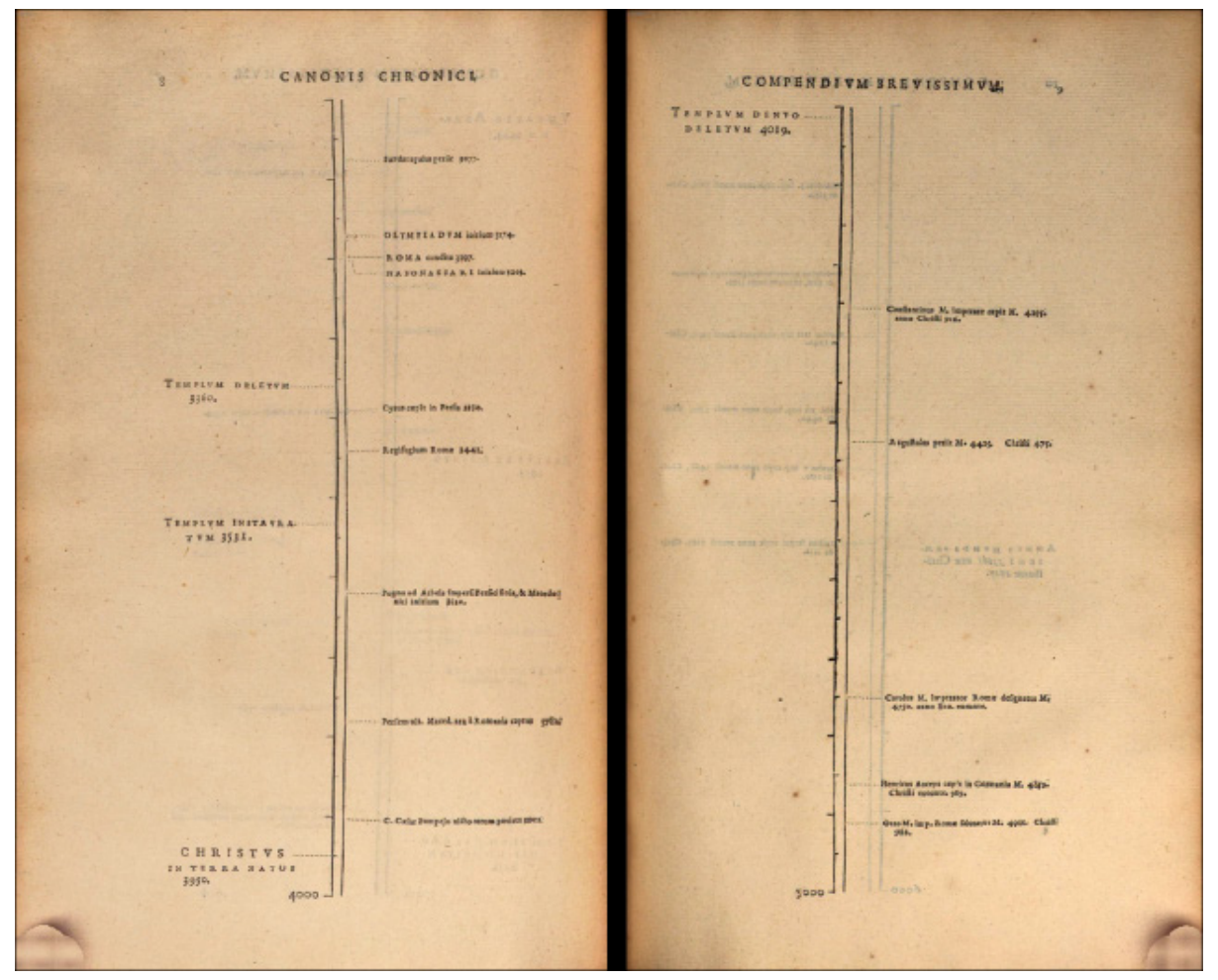

Emmius (1619) (Exemplar: Bayerische Staatsbibliothek München)

Mais adiante na mesma obra, composta, na verdade, de várias cronologias, os traços indicados na régua cronológica passam a indicar o intervalo temporal de um ano. Ou seja, o aumento do volume de texto se traduz na necessidade de mudança de escala gráfico-espacial, algo que já passara a ser uma preocupação recorrente na obra de autores dedicados à representação matemático-cartográfica do tempo e do espaço. Esse é o caso de Gerhard Mercator (1512-1594), que imprime, na cidade protestante de Duisburg, uma nova representação do globo terrestre adaptada para o uso na navegação no mesmo ano em que sua obra de cronologia histórica foi publicada. A Chronologia de Mercator datada de 
1569 deixa à mostra uma proposta matemática de representação e comparação visual de diferentes escalas temporais (Mercator, 1569). Para tanto, Mercator não se preocupara com os espaços vazios, de modo que o fluxo sequencial da passagem do tempo é impresso integralmente na página, mesmo que para uma determinada unidade temporal não haja correspondência no plano dos acontecimentos indicados pelo texto.

Esse padrão morfológico das tabelas históricas inaugurado por Mercator e retomado por Emmius não se configura, no entanto, como o padrão mais recorrente. É na cena universitária de Helmstedt - inaugurada no último quarto do século XVI com apoio de Chytraeus, mestre de Emmius - que Christoph Schrader (1601-1680) publica uma série de tabelas cronológicas que passam a ser as tabelas históricas mais difundidas e reeditadas no Sacro Império Romano Germânico ao longo dos séculos XVII e XVIII.

Na edição de 1652 das Tabulae chronologicae de Schrader, a informação histórica é organizada visualmente sem que se observe qualquer regularidade gráfico-espacial da representação do tempo no papel (Schrader, 1652). E esse é justamente o padrão gráfico das tabelas históricas presentes com mais frequência nas bibliotecas e salas de aula germânicas. Uma característica material dos exemplares remanescentes das obras de Schrader deixa à mostra fortes indícios sobre o contexto de ensino em que as páginas impressas eram utilizadas e justificam o hábito de visita constante às tabelas.

Em um texto introdutório, Schrader indica como suas tabelas deveriam ser encadernadas: "paginas adversas, ideo manes reliquimus, ut tabulas certis locis fixas semper in conspectu habere \& vel transitu discere possis" (Schrader, 1652, p.2b, apud Brendecke, 2005, p.52). Trata-se de uma forma de encadernação de obras impressas conhecida, no século XVII, pela expressão durchschossene Exemplare. Tais exemplares deveriam conter páginas em branco entre as páginas impressas com o objetivo de deixar espaço livre para anotações de alunos e leitores. Por meio dos acréscimos e comentários feitos com a pena, a informação histórica se adensava e se atualizava. ${ }^{6}$

Completar informações dispostas sob a forma de tabela é uma prática que faz parte, na verdade, de uma lógica dos sistemas de coleção e classificação de objetos do conhecimento em vigor ao longo da Idade Moderna e que extrapola o domínio do pensamento histórico. Esse é o caso da teoria taxonômica de Carl Linnaeus (1707-1778) que tem sido interpretada, mais recentemente, como um modelo taxonômico marcado por "práticas complexas de coleção e comparação" (Müller-Wille, 2007, p.542). Tal abertura se deixa ver, por exemplo,

\footnotetext{
${ }^{6}$ Para o caso das anotações marginais na obra de Schrader, observe-se o exemplar das tabelas impressas em 1696 depositado na Herzog August Bibliothek. Cf. Schrader (1696) (Exemplar: Herzog August Bibliothek. Número de catalogação: Xb 40 166). Tendo em vista o caso dos "durchschossene Exemplare", Arndt Brendecke defende a tese de que as tabelas de Schrader abrem espaço para um tipo de conhecimento "performático", para um processo de trabalho necessariamente "intertextual" e "intermediático". Cf. Brendecke (2005, p.50).
} 
na forma de concepção dos manuscritos datados de 1735 e que serviram de base para a obra Species plantarum, publicada entre as décadas de 1740 e 1750. O manuscrito de Linnaeus é composto de fascículos marcados, visualmente, pela presença de grandes espaços em branco à espera de adições, de expansões significativas (Müller-Wille e Scharf, 2009).

\section{Completar informações dispostas sob a forma de tabela é uma prática que faz parte de uma lógica dos sistemas de coleção e classificação de objetos do conhecimento em vigor ao longo da Idade Moderna}

Adições, expansões e atualizações da obra de Schrader prosseguem ao longo do século XVIII. Em uma edição publicada em formato in-folio e datada de 1735 de suas tábuas cronológicas (Schrader, 1735), a distribuição da informação histórica segue um esquema gráfico já utilizado em edições anteriores: as páginas encontram-se divididas ao meio, representando, a linha contínua de corte, o marco cronológico da passagem de um século. ${ }^{7}$

Em função da organização do texto atribuído a Schrader com relação às linhas horizontais contínuas impressas no papel, mais um esforço gráfico se torna evidente, sobretudo na edição em formato in-octavo das Tabvlae chronologicae publicadas em 1765 (Schrader, 1765). As linhas iniciais do texto procuram apresentar uma imagem da simultaneidade.

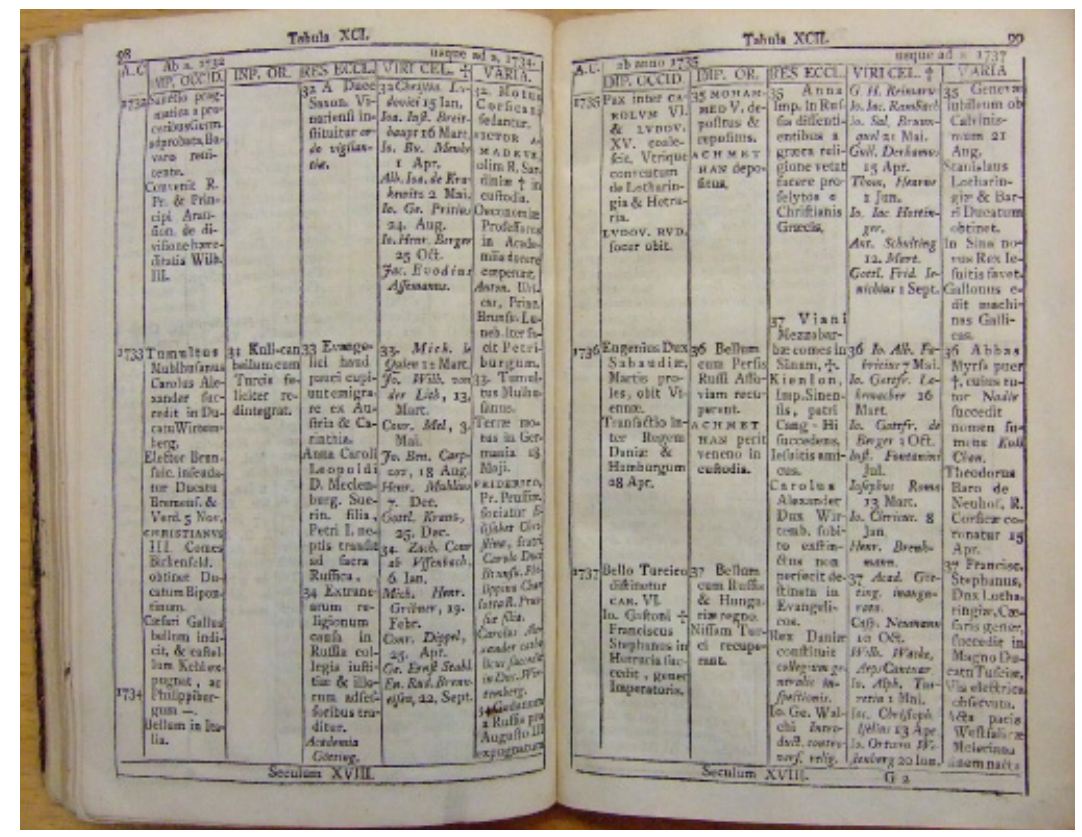

Schrader (1765) (Exemplar: Niedersächsische Staats- und Universitätsbibliothek Göttingen).

${ }^{7}$ Esse mesmo esquema gráfico é seguido na obra Neu erläuterte Zeit- und Jahr-Rechnung, de Jakob Wilhelm von Imhof (1651-1728), publicada sob o pseudônimo de A.N.P.I. em 1699. Cf. Imhof (1699). 
Essa é uma das estratégias de representação visual da informação histórica que passam a ser recorrentes no contexto acadêmico germânico da segunda metade do século XVIII, época em que Johann Christoph Gatterer publica sua Synopsis historiae universalis em Göttingen.

\section{Representação visual da precisão científica: funções das imagens da simultaneidade}

O uso de tabelas sincrônicas como material auxiliar às preleções da Faculdade de Filosofia foi introduzido na Universidade de Göttingen pelo antecessor direto de Gatterer na cátedra de História, Johann David Köhler (1684-1755). A primera edição do catálogo dos cursos ofertados em Göttingen, impressa em 1736, informa em língua latina:

Io. David Koelervs, Historiarum P. P. O. ex tabulis suis chronologicis recensebit historiam vniuersalem seculorum trium priorum a Christo nato, compectantem historiam Romani Imperii, variarum gentium, ecclesiasticam, \& literariam, in praelectionibus publicis ab hora VII. Matutina. ${ }^{8}$

As tábuas mencionadas no anúncio dos cursos e publicadas no mesmo ano de 1736 em 27 fólios sob o título de Chronologia historiae vniversalis encontram-se, via de regra, divididas em quatro colunas nas quais se listam nomes e acontecimentos relacionados, respectivamente, à história bíblica, à história profana, à história eclesiástica e à história literária.

Com a morte de Köhler em 1755, essa tradição didática é retomada por seu filho, Johann Tobias Köhler (1720-1768), e pelo sucessor do pai na Universidade de Göttingen, Gatterer, a partir do semestre de inverno de 1765-1766, ano em que se anuncia que os cursos de história universal serão ministrados com o auxílio de tabelas cronológicas que o novo professor fará imprimir. ${ }^{9}$ As tábuas sincrônicas de Gatterer do grupo A e publicadas inicialmente em 1766 seguem um padrão visual semelhante àquele que se pode observar na Chronologia de Köhler. Some-se, no entanto, à partição tipológica das colunas a importância das linhas horizontais por meio das quais se procura marcar a transição dos séculos, bem como a disposição graficamente alinhada de eventos simultâneos. Ou seja, o padrão de organização visual da informação histórica nas tábuas sincrônicas de Gatterer do grupo A pode ser reconhecido na tradição iniciada em Göttingen por Köhler somada à linguagem gráfica das Tabvlae chronologicae de Schrader.

Para que se possa, no entanto, compreender a lógica que organiza a imagem da simultaneidade nas tábuas do grupo B, é preciso retomar a linhagem historiográfica identificada por Hübler ao final do século XVIII quanto às

${ }^{8}$ CATALOGUVS lectionvm pvblice et privatim in academia georgia avgvsta per aestatem 1736 . Gottingae: Apvd Abramvm Vandenhoeck, 1736. p.5.

${ }^{9} \mathrm{Cf}$. GÖTTINGISCHE Anzeigen von gelehrten Sachen, 109. und 110. Stück, Den 12. und 14. September 1765. Göttingen: Gedrückt bey Johann Albrecht Barmeier. p.882. 
possibilidades de representação, em um único plano, da cronologia e do sincronismo. Hübler lembrara, para além do trabalho de Gatterer, da importância das Tabulae chronologicae de Johann Matthias Hase.

Professor ordinário de matemática na Universidade de Wittenberg, Hase dedica-se igualmente à astronomia e escreve livros de geografia histórica (Ratzel, 1879, p.743-744). Mas é apenas no ano seguinte à sua morte que sai publicada, de sua autoria, uma História Universal provida de tábuas cronológicas e geográficas (Hase, 1743). Igualmente em grande formato $(30,5 \mathrm{~cm} \times 52,8$ $\mathrm{cm}$ ), ainda se publica um atlas histórico atribuído a Hase em 1750 (Hase, 1750), no qual se incluem mapas de geografia bíblica referentes à época de David e Salomão. Nas duas obras, as tábuas de Hase seguem um esquema gráfico claramente comparável àquele que Gatterer irá desenvolver nos fólios do grupo B da Synopsis historiae universalis. ${ }^{10}$

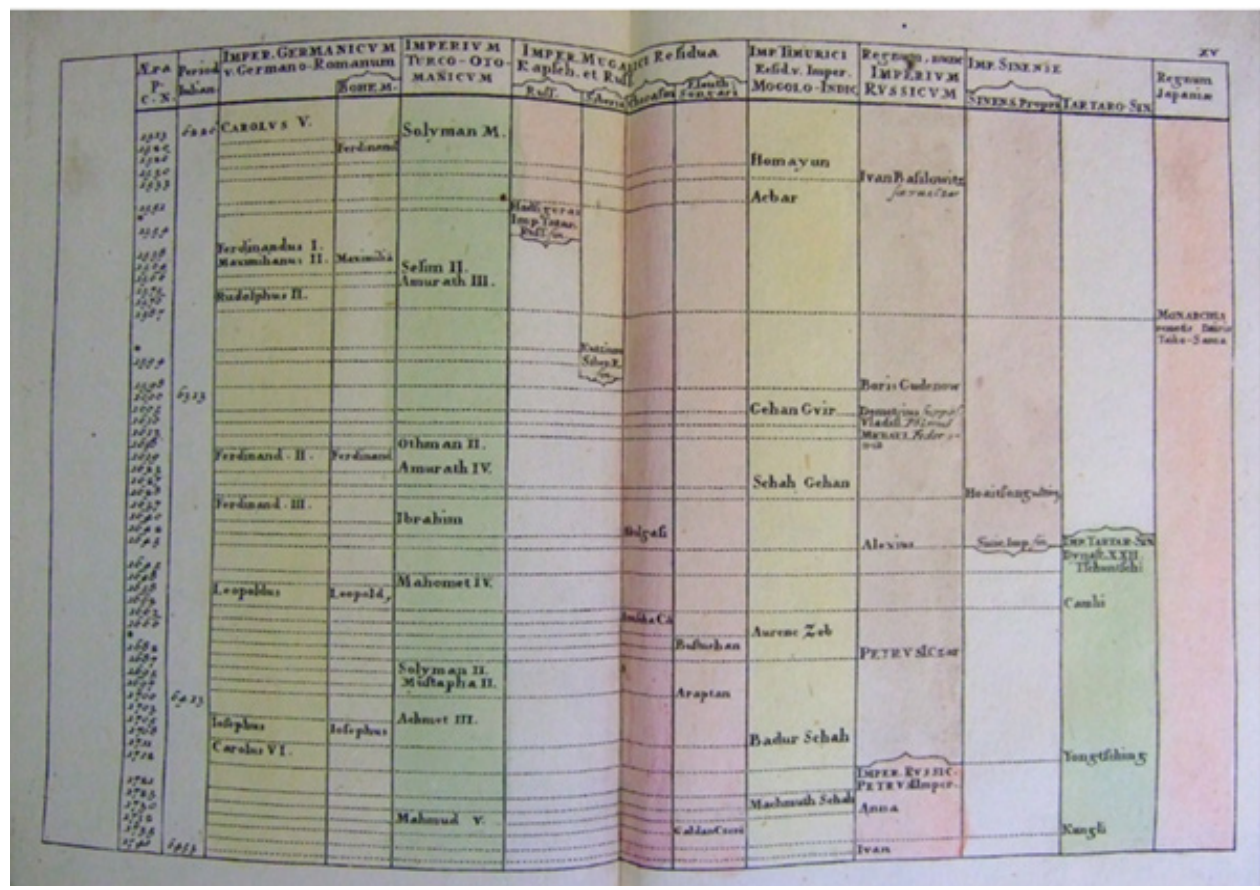

Hase (1750) (Exemplar: Niedersächsische Staats- und Universitätsbibliothek Göttingen).

Tanto no Atlas Histórico, quanto na História Universal de Hase, a representação do fluxo temporal no papel não observa a regularidade matemática de uma escala espacial. No entanto, a edição conta com linhas pontilhadas que têm por função indicar, com precisão gráfica, os marcos cronológicos relacionados a um determinado evento, ou ainda apontar equivalências entre diferentes sistemas de contagem do tempo. A régua e o tracejado seguro das linhas são marcas claras da semântica visual científica que se consolida ao

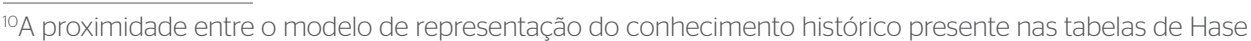
e aquele promovido, posteriomente, por Gatterer foi recentemente analisada por Gierl (2012, p.285-292). 
longo da Idade Moderna europeia, época em que experimentalistas procuravam traduzir o resultado de suas observações empíricas em termos cada vez mais predominantemente quantitativos (Home, 2003, p.371). Trata-se ainda do momento em que surgiam os relógios de marcação acurada do tempo, e que também se disseminava o uso de instrumentos e métodos de "determinação longitudinal de uma orientação geográfica precisa” (Despoix, 2009, p.20). Nos mapas históricos, a informação precisa se expressa, visualmente, ora por meio da observância de uma escala espacial regular, ora por meio do uso de linhas contínuas e pontilhadas com as quais se traçam fronteiras e se indicam equivalências entre elementos representados na imagem, ora ainda por meio do uso controlado da cor sobre o papel. ${ }^{11}$

A adição de pigmento colorido às tábuas históricas pode ter por função suplantar dificuldades de ordem narrativa, para além da função mais restrita de indicação, por meio do contraste, de fronteiras político-culturais. Eis que no mesmo ano em que Gatterer imprime pela segunda vez os seis fólios da Synopsis historiae universalis, Joseph Priestley (1733-1804) esclarece a linguagem visual de que se valera ao publicar $A$ new chart of history: "A história de umas poucas províncias, ou de poucos estados, pode ser exibida e a continuidade dos impérios preservada", argumenta. Algo que, no entanto,

é absolutamente impraticável no caso (...) da história geral, da história universal. Mas esse defeito pode ser corrigido, em grande medida, colorindo as partes divididas do mesmo império da mesma forma, de tal modo que a relação entre as partes possa ser vista de uma só vez. (Priestley, 1786, p.14-15)

O que Priestley sistematiza em 1769, Friedrich Carl Fulda (1724-1788) põe em prática em solo germânico ao insistir no uso da cor em tábuas históricas de grande formato. ${ }^{12}$ Juntamente com sua Charde der Weltgeschichten, Fulda publica no início da década de 1780, em formato in-octavo, um volume intitulado Visão da história mundial (Fulda, 1783); volume este que serve para explicar a lógica de composição do grande quadro montável datado de 1782. Nele, o autor indica que as cores têm uma função tão importante em suas tabelas, que as letras - ou seja, o texto - apenas servem para confirmá-la e explicá-la no detalhe (Fulda, 1783, p.3). Trata-se da inversão do princípio de composição das tabelas históricas que circulavam no início na Idade Moderna europeia, quando o mecanismo de distribuição da informação histórica impressa no papel era dominado, essencialmente, pelo fluxo do texto.

\footnotetext{
"Assim como no Atlas historicvs de Hase, também nos dois conjuntos de mapas preparados por Johann Christoph Gatterer em 1789 a adição controlada de pigmento colorido à imagem impressa tem por função identificar domínios político-culturais distintos. Catalogado sob o título de Atlas / no acervo da biblioteca da Universidade de Göttingen, encontram-se nove planiglobos coloridos em grande formato (tamanho do papel: $62,5 \mathrm{~cm} \times 67,5 \mathrm{~cm}$ ). Sob o título Atlas II, encontram-se colecionados mapas com contornos indicadores de fronteira em cores: quatro em fólio simples e 23 em menor formato. Cf. Gatterer (1789) (Exemplares: Niedersächsische Staats- und Universitätsbibliothek Göttingen. Números de classificação, respectivamente: SUB HSD:GR 2 GEOGR 189 RARA / SUB: 4 GEOGR 189 RARA).

${ }^{12} F u l d a$ (1782) (Exemplar: Niedersächsische Staats- und Universitätsbibliothek Göttingen. Número de classificação: SUB RMAG: 2 H UN I, 462).
} 
No caso da Synopsis de Gatterer, os exemplares remanescentes trazem os dois grupos de tábuas históricas encadernados em ordem distinta, além de serem divergentes no que diz respeito ao uso de pigmento colorido nas duas tábuas do subconjunto menor. ${ }^{13}$ As diferenças na sequência de encadernação dos fólios apontam para a independência relativa dos conjuntos, apesar da unidade tipológica intencional das seis tábuas expressa no título da obra Synopsis historiae universalis, sex tabulis, quarum duae in aes incisae coloribusque illustratae sunt [...]. Mais do que isso: a sequência de leitura das páginas parece apontar para uma dinâmica de uso do material impresso que dispensa o leitor de observar apenas a sucessão da série, uma vez que os dois subconjuntos devem ser eficazes independentemente da ordem em que se encontram dispostos. Quanto ao uso - ou à ausência — de cor, é preciso levar em consideração dois aspectos, quais sejam: as formas de aplicação de pigmento colorido sobre o papel durante o século XVIII e as funções que se podem atribuir a esse tipo de informação visual no interior da obra.

Como a aplicação de cor às imagens impressas era feita, via de regra, à mão, pode-se observar claras divergências entre os exemplares feitos a partir das mesmas matrizes de impressão das tábuas do grupo B na Synopsis historiae universalis. ${ }^{14}$

Ao se observar a função que se pode atribuir à presença de pigmento colorido nas reproduções anteriores, pode-se concluir que, diferentemente de Priestley e Fulda, o uso da cor nas tábuas de Gatterer não acrescenta informação histórica significativa àquela que obedece ao traçado preciso das linhas. $\mathrm{Na}$ Synopsis historiae universalis, as cores servem apenas para destacar fronteiras, e não para indicar continuidades político-culturais. Mas ao assinalar a duração dos povos e reinos nas tábuas do grupo B por meio de linhas, e ao destacá-la

\footnotetext{
${ }^{13} \mathrm{O}$ exemplar depositado na Biblioteca da Universidade de Erlangen-Nürnberg mantém a seguinte ordem de encadernação dos subconjuntos: tábuas I a IV (grupo A) e, posteriormente, tábuas I a II (grupo B), e a essas duas últimas tábuas não foi adicionado o recurso da cor. No exemplar da mesma obra armazenado na Biblioteca da Universidade de Göttingen ocorre inversão da ordem de encadernação dos dois subconjuntos, ambos marcados pela ausência de cor. Já no exemplar disponível para consulta na Biblioteca da Universidade de Halle, os seis fólios encontram-se encadernados na ordem I a IV e I a II, mas ao último conjunto foi aplicado o recurso da cor. Cf. Gatterer (1769) (Exemplares: Universitätsbibliothek Erlangen-Nürnberg. Número de classificação: HOO/2 HIST 20 h; Niedersächsische Staats- und Universitätsbibliothek Göttingen. Número de classificação: 2 H UN II, 488]; Gatterer (1766) (Exemplar: Universitäts- und Landesbibliothek Sachsen-Anhalt. Número de classificação: Ha 179 IZEA / Na 1338).

${ }^{14}$ Para reforçar a tese segundo a qual se aplicava à mão e de forma individual a cor à imagem impressa, devese observar que no exemplar da Biblioteca da Universidade de Tübingen a tábua I é colorida, enquanto que à segunda tábua da mesma edição não foi adicionado o recurso da cor. Compare-se, portanto, os seguintes exemplares em cores: Johann Christopher Gatterer, Synopsis historiae universalis: sex tabulis comprehensa et Academiae Historicae Goettingensi oblata, Goettingae, 1766 (Exemplares: Universitäts- und Landesbibliothek Sachsen-Anhalt, Número de catalogação: Ha 179 IZEA / Na 1338; Gottfried Wilhelm Leibniz Bibliothek/ Niedersächsische Landesbibliothek, Hannover. Número de catalogação: F-A 1001O; Universitätsbibliothek Tübingen. Número de catalogação: Fn 28.2). A completa ausência de cor marca os seguintes exemplares, igualmente consultados: Johann Christopher Gatterer, Synopsis historiae universalis: sex tabulis comprehensa et Academiae Historicae Goettingensi oblata, Goettingae, 1766 (Exemplares: Universitätsbibliothek Leipzig. Número de catalogação: Allg.Gesch.73; Bibliotheca Albertina-Sondersammlungen; Forschungsbibliothek Gotha. Número de catalogação: SPB $2^{\circ}$ 1270.00157). Johann Christopher Gatterer, Synopsis historiae universalis sex tabulis, quarum duae in aes incisae coloribusque illustratae sunt, comprehensa et regio instituto historico Gottingensi, Ed. II, Gottingae; Gothae, 1769 (Exemplares: Universitätsbibliothek Leipzig. Número de catalogação: Allg.Gesch.74; Bibliotheca Albertina-Sondersammlungen; Landesbibliothek Oldenburg. Número de catalogação: GE III 1 A 60; Universitätsbibliothek Rostock. Número de catalogação: Rb-930).
} 


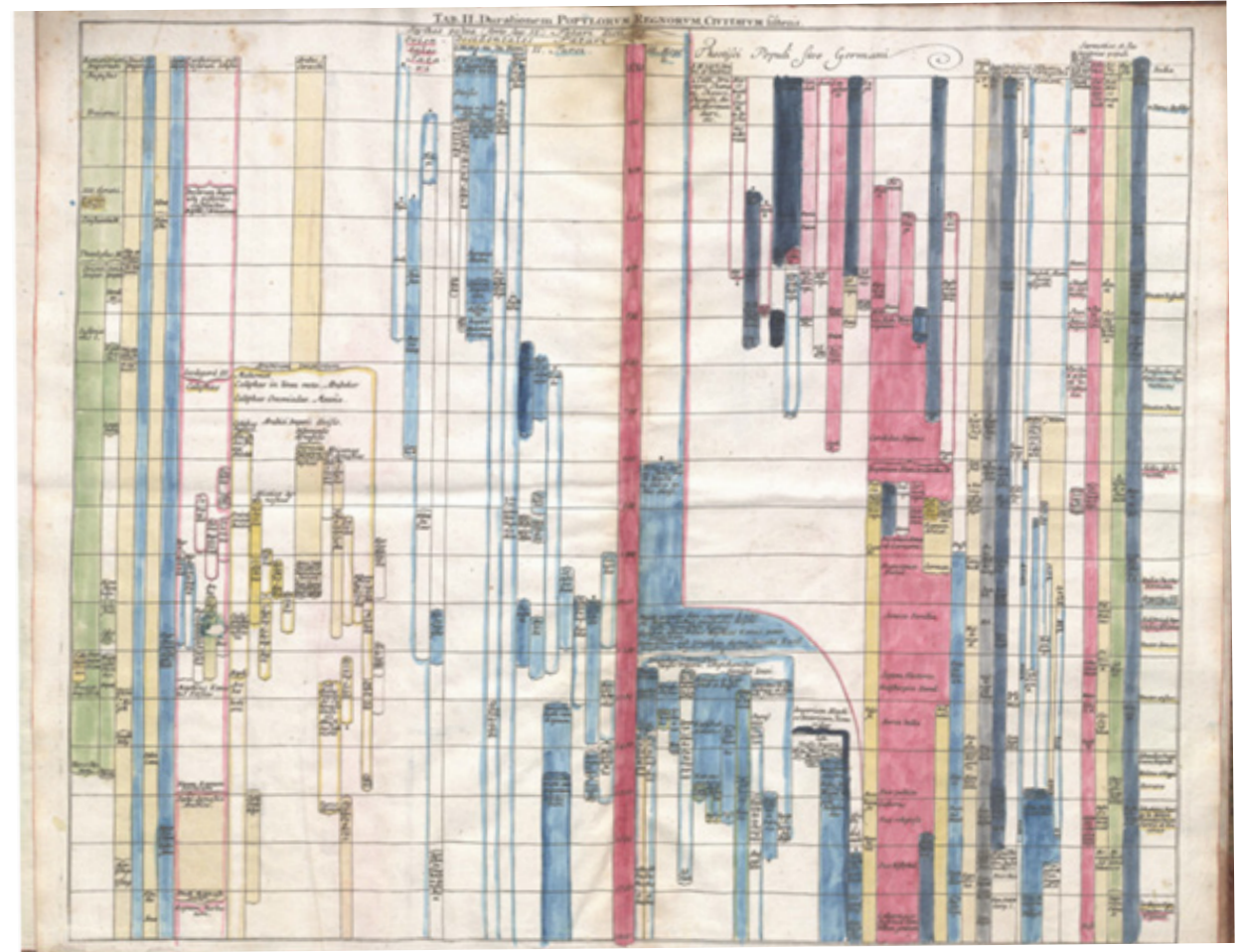

Gatterer (1766) (Exemplar: Gottfried Wilhelm Leibniz Bibliothek/Niedersächsische Landesbibliothek, Hannover. Número de catalogação: F-A 10010). Compare-se o uso da cor entre dois exemplares feitos a partir da mesma matriz de impressão (cf. imagem 2).

por meio das cores, ${ }^{15}$ Gatterer marca visualmente as principais "revoluções" históricas, uma vez que o objetivo de suas tábuas era oferecer, no espaço de apenas um semestre letivo, uma visão sincrônica do todo da história (Gatterer, 1771 , p. ${ }^{\text {(1) }}$. Portanto, o que se verifica na tradição inaugurada em Göttingen por Gatterer é que os atributos morfológicos da imagem da simultaneidade passam a ter clara função cognitiva.

Imagens da simultaneidade e os impasses da narrativa

Em sua Introdução à história universal sincrônica, datada de 1771, Gatterer recorre, não por acaso, às possibilidades de composição das imagens na superfície plana da pintura para enfrentar problemas de composição da narrativa histórica. Para o professor de Göttingen, o todo histórico deve ser imaginado "como em uma pintura, como em um quadro geral [allgemeines Gemälde]" (Gatterer, 1771, p.23), de modo que eventos sincrônicos possam assim ser representados, ainda que apenas dispostos lado a lado.

\footnotetext{
${ }^{15}$ Vejam-se, por exemplo, tanto nas tábuas do grupo B, como naquelas do grupo A, as datas referentes à união das coroas inglesa e escocesa com Jaime I no início do século XVII, ou ainda o grande arco em cor cinza por meio do qual Gatterer assinala continuidades e descontinuidades políticas da história do Império Mongol no início do século XIII e na segunda metade do século XIV. Para a correspondência narrativa dos últimos eventos mencionados, apresentados por meio da sequência cronológica de datas, cf. Gatterer (1771, p.19).
} 
O termo original utilizado por Gatterer para designar "um quadro geral" é Gemälde. No vocabulário do iluminismo tardio germânico, o termo guarda tanto um sentido próprio - pintura sobre uma superfície plana - , quanto outro mais figurado: Gemälde é também, nas belas artes, "a descrição de um objeto sensível por meio de palavras” (Adelung, 1775, vol. 2, col. 542). É certo que ao discorrer sobre a natureza do conhecimento histórico Gatterer se vale, por um lado, de um ponto de contato das artes figurativas com a arte retórica, segundo o qual a descrição vivificante de um objeto por meio das palavras procura despertar sensações visuais seja no ouvinte, seja no leitor (Gatterer, 1767, p.1-38). O núcleo de tal ponto de contato é condensado na expressão latina ut pictura poesis, que, ao menos na leitura da ars poetica de Horácio feita pelos humanistas no começo da Idade Moderna (Lee, 1967, p.3-5; Montanari, 2010, p.958), aproxima, de forma direta, os modos de representação da poesia e da pintura. É nesse sentido que Gatterer defende que "também coisas que nunca sentimos podem ser presentificadas, tanto por meio de descrições pictóricas, quanto por meio do esforço das faculdades da nossa alma". Nesses casos, prossegue, "a alma precisa se valer de duas faculdades para evocar uma presença ideal: a imaginação e a força poética".16 Mas por conta da dificuldade de composição narrativa da prosa historiográfica, Gatterer procura ultrapassar a função retórica clássica do princípio latino ut pictura poesis. Para tanto, recorre aos atributos morfológicos da imagem pictórica para enfrentar um problema de representação narrativa — e gráfica da simultaneidade dos acontecimentos históricos.

\section{Ao discorrer sobre a natureza do conhecimento histórico \\ Gatterer se vale, de um ponto de contato das artes figurativas com a arte retórica}

O esforço tem início na época em que Gatterer publica tanto um esboço da história universal (1765), quanto suas tábuas sincrônicas (1766-1769), reflete sobre o alcance das duas faculdades da alma, a saber: a imaginação e a força poética (1767), e defende que a história universal deve estar para a história, assim como os mapas do globo terrestre estão para a geografia (1767). "A história universal deve, portanto, ser breve; deve se ocupar apenas com as principais revoluções", conclui.

Deve não apenas narrar, mas sobretudo esboçar [vormalen], em uma imagem reduzida, o contexto geral das curiosidades extraordinárias nas histórias especiais, e a simultaneidade de todas as grandes mudanças no solo terrestre, nos estados, na religião, nas artes e ciências, no comércio e na navegação. (Gatterer, 1767, p.62-63)

${ }^{16}$ Gatterer (1767, p.8). Em um dos mais importantes estudos de estética publicados em língua alemã ao longo da segunda metade do século XVIII, Johann Georg Sulzer (1720-1799) define a força poética (Dichtungskraft) como a capacidade da alma de evocar objetos perceptíveis aos sentidos; objetos estes que, por sua vez, nunca foram percebidos empiricamente. Cf. Sulzer (1771, vol. 1, p.259). 
A eficácia da complementariedade explicitada na passagem entre as atividades de narrar e de esboçar o todo da história do mundo em uma imagem reduzida é posta à prova por Gatterer nas tábuas do grupo B na Synopsis historiae universalis. Nelas, não é a descrição verbal do objeto que desperta sensações no leitor, mas sim os atributos morfológicos da imagem por meio da qual se representa a simultaneidade em um sistema de acontecimentos históricos.

É certo que o efeito mais evidente das tábuas históricas consiste, à primeira vista, em promover o acúmulo do "conhecimento histórico por meio da redução de seu teor narrativo" (Steiner, 2010, p.246), uma vez que nelas não há espaço nem para diálogos, nem para outras formas de artifícios retóricos que caracterizam a produção historiográfica da época. Em perspectiva histórica, tal efeito parece, à primeira vista, contrariar a tese de que houve uma crescente ampliação do teor narrativo do conhecimento histórico ao longo da história da historiografia moderna. É nesse sentido que, em contraposição ao que se define por história como um gênero narrativo propriamente dito, outras duas formas básicas da representação histórica - a saber: os anais e a crônica foram caracterizadas em termos de imperfeição historiográfica no que diz respeito às características da linguagem mobilizadas em cada gênero para o tratamento explicativo do fato histórico. ${ }^{17}$ À narrativização, Hayden White opõe a descrição estática de um estado de coisas (White, 2000, p.403-404), motivo pelo qual a crônica seria uma forma fadada ao fracasso (White, 1987, p.5 e 16).

Apoiado na tese de White, Daniel Fulda, na sua obra seminal sobre o surgimento da escrita histórica moderna na Alemanha, associa a forma da crônica ao gênero das tabelas históricas à época do Iluminismo tardio. Para Fulda, também nas tabelas falta quase que completamente o elemento narrativo, de tal modo que elas não poderiam contribuir para o desenvolvimento da escrita da história (Fulda, 1996, p.202-203), por sua vez necessariamente caracterizada pela narratividade (Fulda, 1996, p.208). Mais ainda: elas seriam um obstáculo ao desenvolvimento da narrativa histórica moderna, uma vez que a linguagem das tabelas é identificada com o retorno a um gênero historiográfico supostamente superado (Fulda, 1996, p.206-208). Tabelas e narração, conclui Fulda, são formas antípodas e excludentes de representação do conhecimento histórico (Fulda, 1996, p.208).

No entanto, é preciso aqui insistir na tese de que essa leitura do lugar epistemológico das tabelas históricas ao longo do processo de cientifização do conhecimento histórico moderno é essencialmente desfocada. ${ }^{18}$ Tal falta de foco - eis a tese central deste artigo — pode ser reconhecida em três planos.

\footnotetext{
${ }^{17 W h i t e ~(1987, ~ p .4) . ~ E m ~ p e r s p e c t i v a ~ h i s t o r i o g r a ́ f i c a, ~ o ~ g e ̂ n e r o ~ d o s ~ a n a i s ~ p r e c e d e ~ a ̀ q u e l e ~ d a s ~ c r o ̂ n i c a s, ~ s e n d o ~}$ estas "um relato mais expandido dos eventos" igualmente organizados de forma cronológica. Cf. Foot (2012, p.347). Ainda sobre a gradação evolutiva estabelecida entre acumulação, série, sequência e narrativização dos acontecimentos históricos no pensamento de Hayden White, cf. White (1973, p.5; 2000, p.393).

${ }^{18}$ Nesse sentido, cf. Steiner (2008, p.261). Veja também as leituras mais recentes das tabelas históricas feitas por Arndt Brendecke, Daniel Rosenberg e Anthony Grafton. Cf. sobretudo: Brendecke (2004, p.157-189); Rosenberg e Grafton (2010). Especificamente sobre o caso das tabelas publicadas por Johann Christoph Gatterer, veja-se o competente trabalho de Gierl (2012). Trata-se de obras mais inovadoras que procuram ultrapassar a leitura fundamentalmente logocêntrica da constituição do pensamento histórico moderno.
} 
Em primeiro lugar, é parcial toda leitura do valor epistemológico das tabelas históricas que perde de vista a oralidade e o caráter performático intrínseco ao gênero. O conjunto de tábuas publicado por Gatterer nos fornece um indício importante nessa direção. A ordem diversa de encadernação dos seis fólios é prova material de que as imagens não foram concebidas para ser lidas necessariamente um uma sequência linear. Ao contrário: elas serviam ao ritmo dado pelo docente no contexto das preleções acadêmicas. Nesse sentido, Johann Stephan Pütter (1725-1807) é testemunha contemporânea dos cursos oferecidos por Gatterer na Universidade de Göttingen. Pütter destaca que ao abordar as revoluções tanto no solo terrestre, quanto entre grandes estados e povos, Gatterer as descrevia "não tão somente com palavras, mas também" as representava "em parte nas tábuas genealógicas feitas para esse fim, em parte nas tabelas sincrônicas, em parte nos planiglobos especialmente iluminados (...)" (Pütter, 1788, p.343). Já nos cursos de história universal, diz ainda Pütter, Gatterer se valia igualmente de tábuas genealógicas, tabelas sincrônicas e planiglobos "para oferecer uma melhor visão geral do todo" (Pütter, 1788, p.343).

Outros indícios do caráter performático das tabelas históricas são fornecidos, como já mencionado, pelas anotações que remontam sobretudo ao contexto oral do ensino e que foram deixadas pelos alunos nos exemplares das obras. Todavia, não se pretende aqui defender que o uso performático das tabelas históricas em sala de aula aponta para a recomposição narrativa do conhecimento histórico (Brendecke, 2005, p.60-61). Pretende-se, antes, afirmar que à época do Iluminismo tardio o conhecimento histórico não se resume à prática da escrita historiográfica. Mais ainda: a informação visual passa a ser um componente importante do processo de cientifização da história, como se procura aqui comprovar ao expor o segundo motivo pelo qual análises exclusivamente logocêntricas da história da historiografia perdem, com frequência, o foco.

O segundo problema grave que se aponta na leitura parcial da função das tábuas históricas na Idade Moderna se relaciona com o deslocamento que se faz, em nome da ênfase narrativista, do quadro epistemológico em função do qual era possível acumular e produzir conhecimento científico na segunda metade do século XVIII. Trata-se da época em que a história passa a ser considerada uma ciência empírica que se valia, como tal, dos métodos empregados por suas ciências auxiliares - perspectiva esta destacada nas diretrizes de trabalho traçadas no Instituto Real de Ciências Históricas dirigido por Gatterer. Nesse contexto, as tábuas sincrônicas assumem a forma de um gênero historiográfico no qual se cruzam os resultados de pesquisa das ciências auxiliares da história, sobretudo da genealogia e da cronologia. Se a proximidade da cronologia com o gênero historiográfico das tabelas históricas é bastante evidente, vejamos ainda rapidamente como os estudos de genealogia igualmente se expressam, na época das Luzes, sob a forma de tabelas e diagramas - ambos igualmente identificados por Gatterer como tábuas, como tabulae.

Gatterer publica, em 1790, um conjunto de 32 tábuas genealógicas de famílias (Gatterer, 1790). "Entre os homens, a genealogia existe antes mesmo 
da história (...)", já definira o autor. A genealogia dispõe os nomes em tabelas com ajuda das quais é possível localizar e ordenar os "conceitos que se encontram em conexão" (Gatterer, 1788, p.5). Até então, prossegue Gatterer, "apenas 5 ou 6 formas de tábuas genealógicas" existiam. Entre elas, diferenciam-se as tábuas históricas das tábuas sincrônicas no contexto da genealogia (Gatterer, 1788, p.17). Quanto às últimas — algo ainda não muito comum, adverte - , trata-se de tábuas "com mais de uma família, que por motivos distintos são colocadas lado a lado; seja para se poder identificar o sincronismo entre as mesmas" (Gatterer, 1788, p.19), algo que facilitaria o rápido olhar histórico sobre os acontecimentos, ou ainda para mostrar o parentesco entre elas. Desse modo, as tábuas sincrônicas expressam relações temporais que podem ser rapidamente apreendidas pela visão. Tal eficácia cognitiva é análoga àquela que pode ser atribuída às tábuas genealógicas: “Uma relação que levaria muito tempo para explicar em palavras, de tal modo que poderíamos perder o fio da meada [da narrativa] ('ela é a esposa de um primo de segundo grau da minha madrasta'), pode ser observada em uma árvore genealógica com um único olhar" (Gombrich, 2002, p.149-150).

Na obra de Gatterer, as tábuas históricas se diferenciam das tábuas meramente genealógicas por apresentar não apenas as informações relativas às famílias, mas também as "descrições da vida ou a narrativa dos acontecimentos ou ações" (Gatterer, 1788, p.20), de forma que, nesse caso, genealogia e história se imiscuem. Assim, pode-se descrever os dois padrões gráficos que se encontram presentes no conjunto de seis fólios publicados em 1766 e republicados em 1769. Por um lado, o autor segue a tradição do gênero na variante já disseminada em Göttingen na obra de seu antecessor Köhler e apresenta, ao longo das linhas e colunas, breves descrições dos acontecimentos importantes da história do mundo. Por outro, Gatterer se vale de procedimentos próprios à genealogia para acompanhar de perto o sincronismo dos povos na história da humanidade. Some-se a tal perspectiva o fato de que ele concebe sua Synopsis historiae universalis levando em conta uma forma de representação cartográfica precisa do conhecimento. ${ }^{19}$ Portanto, a precisão científica das ciências auxiliares que se expressam por meio de imagens é elemento intrínseco - e não forma antípoda - do processo de constituição do conhecimento histórico moderno. Ao observar o percurso genealógico dos acontecimentos do mundo com precisão, procurava-se representar, por meio dos atributos morfológicos da imagem pictórica, possíveis correlações entre os acontecimentos da história dos povos. No conjunto dos seis fólios publicados por Gatterer, a informação visual é fonte do conhecimento histórico.

Em terceiro lugar, as tábuas cumprem, no interior da reflexão historiográfica do professor em Göttingen, uma função ainda mais definida. Elas não têm por objetivo simplesmente traduzir em linguagem visual o conteúdo expresso verbalmente no texto; antes, como imagens, procuram superar as dificuldades

${ }^{19}$ Martin Gierl define, recentemente, o modelo de ciência promovido por Johann Christoph Gatterer em termos de precisão. Cf. Gierl (2012). Nesse sentido, cf. também: Steiner (2008, p.95). 
da representação narrativa. Ao acrescentar à narrativa histórica a função cognitiva que se pode, nesse caso, atribuir às imagens pictóricas não figurativas, Gatterer se aproxima das práticas científicas da Idade Moderna que conferem à visão um sentido privilegiado (Siegel, 2009, p.160) e que reduzem a abstrações essenciais os elementos integrantes de um sistema universal (Freedberg, 2002, sobretudo p.349, 396, 397). A construção de uma síntese redutora é resultado das características formais desse tipo de imagem (Bender e Marrinan, 2010, p.7). Desse modo, as partes expressas no conjunto final do sistema não se somam, mas se encontram potencialmente relacionadas em uma única história, em uma única imagem da simultaneidade.

“O artigo apresenta os resultados da pesquisa de pós-doutorado realizada da USP com apoio da Fapesp. Algumas ideias centrais desenvolvidas no artigo foram discutidas em agosto de 2012 na UFOP e em julho de 2013 na Universidade de Gent, com apoio da Finatec. As reflexões aqui apresentadas fazem parte, atualmente, de um projeto de pesquisa mais amplo sobre "Informação Visual e Conhecimento Histórico no Iluminismo alemão", apoiado pelo CNPq. O autor agradece a Arthur Alfaix Assis pela leitura cautelosa do manuscrito e por suas valiosas sugestões."

\section{Referências bibliográficas}

ADELUNG, Johann Christoph. Versuch eines vollständigen grammatisch-kritischen Wörterbuches der Hochdeutschen Mundart. Leipzig: Bernhard Christoph Breitkopf, 1775. vol. 2.

ARAÚJO, André de Melo. Weltgeschichte in Göttingen. Eine Studie über das spätaufklärerische universalhistorische Denken, 1756-1815. Bielefeld: transcript, 2012.

BAUMGARTEN, Hermann. Sleidan, Johann. Allgemeine Deutsche Biographie, vol. 34, p.454-461, 1892. Disponível em: http://www.deutsche-biographie.de/pnd118748440.html?anchor=adb. Acesso em: 15 out. 2014.

BENDER, John; MARRINAN, Michael. The culture of diagram. Stanford: Stanford University Press, 2010.

BRENDECKE, Arndt. 'Durchschossene Exemplare'. Über eine Schittstelle zwischen Handschrift und Druck. In: ESTERMANN, Monika et al. (Org.). Archiv für Geschichte des Buchwesens, Vol. 59. Berlin: De Gruyter, 2005.

BRENDECKE, Arndt. Darstellungsmaßtäbe universalhistorischer Zeit. in: BRENDECKE, Arndt; FUCHS, Ralf-Peter; KOLLER, Edith (Org.). Die Autorität der Zeit in der Frühen Neuzeit. Münster: Lit Verlag, 2007. p.491-521.

BRENDECKE, Arndt. Tabellenwerke in der Praxis der frühneuzeitlichen Geschichtsvermittlung. In: STAMMEN, Theo; WEBER, Wolfgang E. J. (Org.). Wissenssicherung, Wissensordnung und Wissensverarbeitung. Das europäische Modell der Enzyklopädien. Berlin: Akademie Verlag, 2004. CATALOGUVS lectionvm pvblice et privatim in academia georgia avgvsta per aestatem 1736 . Gottingae: Apvd Abramvm Vandenhoeck, 1736.

CHYTRAEUS, David. Chronologia Historiae Herodoti et Thucydidis. Argentorati, 1563.

CONRAD, Marcus. Geschichte(n) und Geschäfte. Die Publikation der 'Allgemeinen Welthistorie' im Verlag Gebauer in Halle (1744-1814). Wiesbaden: Harrassowitz Verlag, 2010.

DASTON, Lorraine. The empire of observation, 1600-1800. In: DASTON, Lorraine; LUNBECK, Elizabeth (Org.). Histories of scientific observation. Chicago; London: The University of Chicago Press, 2011. 
DESPOIX, Philippe. Die Welt vermessen. Dispositive der Entdeckungsreise im Zeitalter der Aufklärung. Göttingen: Wallstein, 2009.

EMMIUS, Ubbo. Opvs Chronologicum Novvm, Plvribvs Partibvs Constans (...). Groningae, 1619. FOOT, Sarah. Annals and chronicles in Western Europe. In: FOOT, Sarah; ROBINSON, Chase F. (Org.). The Oxford history of historical writing, vol. 2: 400-1400. Oxford: Oxford University Press, 2012.

FREEDBERG, David. The eye of the Lynx. Galileo, his friends, and the beginnings of modern natural history. Chicago; London: The Chicago University Press, 2002.

FULDA, Daniel. Wissenschaft aus Kunst. DieEntstehung der modernen deutschen Geschichtsschreibung. 1760-1860. Berlin: De Gruyter, 1996.

FULDA, Friedrich Carl. Charde der Weltgeschichten. Auf Kosten Conrad Heinrich Stage, Buchhaendler in Augsburg. In Druck verfertiget zu Basel bey W. Haas, 1782.

FULDA, Friedrich Carl. Ueberblick der Weltgeschichten, zur Erläuterung der Geschichtcharte, von dem Verfasser derselben. Augsburg: Conrad Heinrich Stage, 1783.

FUNCK, Johann. Chronologia Hoc Est (...). Norimberga, 1545.

FUNCK, Johann. Chronologia hoc est omnium temporum et annorum ab initio mundi (...). Regiomonte Prussiae, 1552.

GATTERER, Johann Christoph. Abriß der Genealogie. Göttingen: Vandenhoeck und Ruprecht, 1788. GATTERER, Johann Christoph. Atlas I: Fluss-Plan, 1789.

GATTERER, Johann Christoph. Atlas II: Kleine Special-Karten, 1789.

GATTERER, Johann Christoph. Einleitung in die synchronische Universalhistorie, zur Erläuterung seiner synchronistischen Tabellen, Zweiter Theil der Universalhistorie oder zusammenhängende Erzählung der grosen Weltbegebenheiten. Göttingen: Im Verlag der Wittwe Vandenhoek, 1771. GATTERER, Johann Christoph. J. C. Gatterer vom historischen Plan, und der darauf sich gründenden Zusammenfügung der Erzählungen. Allgemeine historische Bibliothek von Mitgliedern des königlichen Instituts der historischen Wissenschaften zu Göttingen, Halle, vol. 1, 1767.

GATTERER, Johann Christoph. J. C. Gatterers Vorrede von der Evidenz in der Geschichtskunde. Die Allgemeine Welthistorie, die in England durch eine Gesellschaft von Gelehrten ausgefertiget worden. Vol. 1. Halle: Johann Justinus Gebauer, 1767.

GATTERER, Johann Christoph. Johann Christoph Gatterers Stammtafeln zur Weltgeschichte, wie auch zur Europäischen Staaten- und Reichshistorie, Erste Sammlung: von Tafel 1 bis und mit 32. Göttingen: Im Verlag der Vandenhoek- und Ruprechtschen Buchhandlung, 1790.

GATTERER, Johann Christopher. Synopsis historiae universalis sex tabulis, quarum duae in aes incisae coloribusque illustratae sunt, comprehensa et regio instituto historico Gottingensi (...). Goettingae et Gothae Impensis Ioh. Christiani Dieterich, 1769.

GATTERER, Johann Christopher. Synopsis historiae universalis sex tabulis, quarum duae in aes incisae coloribusque illustratae sunt, comprehensa et regio instituto historico Gottingensi, Ed. II. Gottingae: Gothae, 1769.

GATTERER, Johann Christopher. Synopsis historiae universalis: sex tabulis comprehensa et Academiae Historicae Goettingensi oblata. Goettingae, 1766.

GATTERER, Johann Christopher. Synopsis historiae vniversalis, Sex Tabvlis, Qvarvm Dvae In Aes Incisae Coloribusque Illvstratae Sunt, Comprehensa Et Academiae Historicae Goettingensi Oblata. Goettingae: Selbstverlag, 1766.

GIERL, Martin. Geschichte als präzisierte Wissenschaft. Johann Christoph Gatterer und die Historiographie des 18. Jahrhunderts im ganzen Umfang. Stuttgart-Bad Cannstatt: FrommannHolzboog, 2012.

GIERL, Martin. Tabelle. In: JAEGER, Friedrich (Org.). Enzyklopädie der Neuzeit, Vol. 13. Stuttgart: J. B. Metzler, 2011.

GOMBRICH, E. H. The visual image: its place in communication [1972]. In: GOMBRICH, E. $\mathrm{H}$. The image \& the eye. Further studies in the psychology of pictorial representation. London: Phaidon, 2002.

GÖTTINGISCHE Anzeigen von gelehrten Sachen, 109. und 110. Stück, Den 12. und 14. September 1765. Göttingen: Gedrückt bey Johann Albrecht Barmeier.

GRAFTON, Anthony; WILLIAMS, Megan. Christianity and the transformation of the book. Origen, Eusebius, and the library of Caesarea. Cambridge: Harvard University Press, 2008. 
HASE, Johann Matthias. Atlas historicvs comprehendens imperia maxima sev monarchias orbis antiqvi historice, chonologice et geographice representatas. Studio Ioannis Matthiae Hasii M. pp. designatus, et impensis Homannianorum Heredum Compositus ita et publicatus, 1750.

HASE, Johann Matthias. Historiae vniversalis politicae (...). Norimbergae: Imprensis Heredvm Homannianorvm et Lipsiae in Commissis Joan. Fridr. Gleditschii, 1743.

HOME, R. W. Mechanics and experimental physics. In: PORTER, Roy (Org.). The Cambridge history of science, Vol. 4: eighteenth-century science. Cambridge: Cambridge University Press, 2003.

HÜBLER, Daniel Gotthold Joseph. Synchronistische Tabellen der Völkergeschichte / hauptsächlich nach Herrn Hofrath Gatterers Versuch einer allgemeinen Weltgeschichte, Erste Lieferung, Zweite sehr vermehrte Ausgabe. Freyberg: In der Crazischen Buchhandlung, 1799.

IGGERS, Georg G. The European context of eighteenth-century German Enlightenment historiography. In: BÖDEKER, Hans Erich; IGGERS, Georg G.; KNUDSEN, Jonathan B.; REILL, Peter H. (Org.). Aufklärung und Geschichte. Studien zur deutschen Geschichtswissenschaft im 18. Jahrhundert. Göttingen: Vandenhoeck \& Ruprecht, 1992. p.225-245.

IGGERS, Georg G. The professionalization of historical studies and the guiding assumptions of modern historical thought. In: KRAMER, Lloyd; MAZA, Sarah (Org.). A companion to Western historical thought. Malden: Blackwell, 2002.

IGGERS, Georg G.; WANG, Q. Edward. A global history of modern historiography. Harlow: Pearson, 2008.

IMHOF, Jakob Wilhelm von. Neu erläuterte Zeit- und Jahr-Rechnung (...). Lüneburg, 1699.

JAEGER, Friedrich; RÜSEN, Jörn. Geschichte des Historismus. Eine Einführung. München: Beck, 1992.

JORDHEIM, Helge. Introduction: multiple times and the work of synchronization. History and Theory, vol. 53, p.498-518, dez. 2014.

LEE, Rensselaer W. Ut pictura poesis. The humanistic theory of painting. New York, Norton, 1967. MERCATOR, Gerhard. Chronologia, Hoc Est Temporvm Demonstratio Exactissima, Ab Initio Mvndi, Vsque Ad Annvm Domini M.D.LXVIII. Ex Eclipsibvs Et Observationibvs Astronomicis omnium temporum (...) concinnata. Coloniae Agrippinae, 1569.

MONTANARI, Tomaso. "ut pictura poesis". In: GRAFTON, Anthony; MOST, Glenn W.; SETTIS, Salvatore (Org.). The classical tradition. Cambridge: Harvard University Press, 2010.

MUHLACK, Ulrich. Geschichtswissenschaft im Humanismus und in der Aufklärung. Die Vorgeschichte des Historismus. München: Beck, 1991.

MÜLLER-WILLE, Staffan. Collection and collation: theory and practice of Linnaean botany. Studies in History and Philosophy of Biological and Biomedical Sciences, vol. 38, 2007.

MÜLLER-WILLE, Staffan; SCHARF, Sara. Indexing nature: Carl Linnaeus (1707-1778) and his fact-gathering strategies. Working Papers on The Nature of Evidence: How Well Do 'Facts' Travel?, N. 36/08, jan. 2009.

PHRYGIO, Paulus Constantinus. Chronicum Regum Regnorvmqve Omnivm Catalogum, Et Perpetuum ab exordio mundi temporum, seculorumq[ue] seriem complectens, ex optimis quibusq[ue] Hebraeis, Graecis \& Latinis autoribus congestum. Basileae, 1534.

PRIESTLEY, Joseph. A description of a new chart of history, containing a view of the principal revolutions of empire that have taken place in the world. The sixth edition, corrected. London: Printed for J. Johnson, 1786.

PÜTTER, Johann Stephan. Versuch einer academischen Gelehrten-Geschichte von der Georg-AugustusUniversität zu Göttingen, Vol. 2. Göttingen: Im Vandenhoeck-Ruprechtischem Verlage, 1788.

RATZEL, Friedrich. Hasius, Johann Matthias. Allgemeine Deutsche Biographie, vol. 10, p.743-744, 1879. Disponível em: http://www.deutsche-biographie.de/pnd100352243.html?anchor=adb. Acesso em: 17 out. 2014.

REILL, Peter Hanns. The German Enlightenment and the rise of historicism. Berkeley: University of California Press, 1975.

ROSENBERG, Daniel; GRAFTON, Anthony. Cartographies of time. A history of the timeline. New York: Princeton Architectural Press, 2010.

SCHRADER, Christoph. Christophori Schraderi Tabulae Chronologicae a Prima Rerum Origine ad Natum Christum (...). Helmstedt: Georg-Wolffgangi Hammii, 1696.

SCHRADER, Christoph. Christophori Schraderi Tabvlae chronologicae a prima rervm origine et inde ad nostra tempora (...). Brvnsvigae: Svmtibvs Lvdolphi Schro[?], 1735. 
SCHRADER, Christoph. Christophori Schraderi Tabvlae Chronologicae A prima rervm origine et inde ad nostra tempora (...). Brvnsvici: Imprensis haeredvm B. Lvdolphi Schroederi, 1765. SCHRADER, Christoph. Tabvlae chronologicae a prima rervm origine ad civilii caesaris monarchiam. Helmaestadi: Henningi Mvlleri, 1652.

SIEGEL, Steffen. Tabula. Figuren der Ordnung um 1600. Berlin: Akademie Verlag, 2009.

SLEIDANUS, Johannes. Tabulae in libros historiarum de religione et republica Jo. Sleidani. Argentoratum, 1557.

STADT-Hannöversche Schul-Ordnung. Hannover: Gedruckt bey Holwein, 1717.

STEINER, Benjamin. Akkumulation und Reduktion. Der Umgang mit Pluralisierung historischen Wissens in frühneuzeitlichen Tabellenwerken. In: MÜLLER, Jan-Dirk; OESTERREICHER, Wulf; VOLLHARDT, Friedrich (Org.). Pluralisierungen. Konzepte zur Erfassung der Frühen Neuzeit. Berlin; New York: De Gruyter, 2010.

STEINER, Benjamin. Die Ordnung der Geschichte. Historische Tabellenwerke in der Frühen Neuzeit. Köln: Böhlau, 2008.

SULZER, Johann Georg. Allgemeine Theorie der schönen Künste. Leipzig: Weidemann und Reich, 1771. vol. 1.

VÖLKEL, Markus. German historical writing from the reformation to the enlightenment. In: RABASA, José; SATO, Masayuki; TORTAROLO, Edoardo; WOOLF, Daniel (Org.). The Oxford history of historical writing, Vol. 3: 1400-1800, Oxford: Oxford University Press, 2012.

WHITE, Hayden. An old question raised again: is historiography art or science? (response to Iggers). Rethinking History, vol. 4, n. 3, 2000.

WHITE, Hayden. Metahistory. The historical imagination in nineteenth-century Europe. Baltimore; London: The Johns Hopkins University Press, 1973

WHITE, Hayden. The value of narrativity in the representation of reality. In: WHITE, Hayden. The content of the form. Narrative discourse and historical representation. Baltimore; London: The Johns Hopkins University Press, 1987. 